\title{
TELEGRAPHING WITHOUT WIRES - AN EXPERIMENT.
}

BY \$. J. M. BEAR.

Materials.-A tub of water, ten cells voltaic battery, two copper earth-plates, one zinc earth-plate, and one porous cell, containing a copper plate, immersed in a solution of sulphate of copper, making the fourth ground connection; a relay, or other receiving instrument, of about two hundred ohms resistance, and a transmitting key.

Arrangement of Parts.-All of the battery outside of the tub, with key in circuit, is connected with the water at one part of the tub, and the relay is connected to the water directly opposite. The zinc plate of battery is connected with copper plate in water, and copper plate of battery is in connection with zinc plate in water. These battery terminals in the tub may be quite close together, but must not be in metallic contact with each other. The relay has one terminal in connection with a copper plate in the water, and the other terminal connected with the copper in porous cell in the water; and these two last connections may also be close to each other.

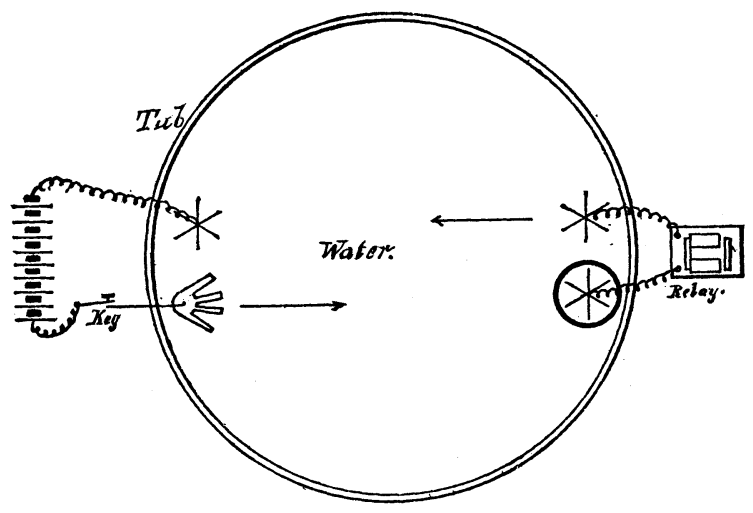

Now, by opening and closing the battery circuit outside the tub, signals may be heard from the relay in response. 
Thus, regardless of the relative distance between the groundplates, electric impulses are transmitted through the water without any insulation between the outgoing and incoming current.

In this way, two continuous currents may pass each other closely in opposite directions at the same time, in the same conductor; or, in other words, the same current passes itself closely in the same conductor; or, if you please, the positive and negative currents are uninsulated in the same narrow circuit.

Then, what prevents the battery current from crossing over between the earth-plates at the sending station? A part of it does so short-circuit, whether an uninsulated wire is used for half the circuit, which we shall see further on, or as above without any wire.

The resistance of water between the sending earth-plates is probably but a few ohms, and yet we have enough of the current out and returned through many times greater resistance of water, to operate the relay, itself of two hundred ohms resistance.

Then, what is the resistance between the sending earth-plates, that causes so much of the current to take the apparently longer route? May it not be the resistance of opposing polarity? For here we have the circuit at the sending-end from the zinc terminal of the battery to and through another active zinc in the tub before it reaches the copper terminal of the battery. It is assumed that the copper earth-plates in the water in the tub are practically inactive, that is, not generating any electricity, but only performing the simple functions of conductors, or circuit connections. What is meant by opposing polarity, is the electrically active plates of same name repelling the passage of a current direct between a pair. On the other hand, we have the inviting or downhill route from active zinc plate in tub to the active copper plate in porous cell-this copper plate made active by the sulphate of copper liquid surrounding it.

It is not that the conducting body of water is so much wider or larger between the sender and receiver than between the sending earth-plates, that we have this result; for, separating the sending earth-plates the same distance as to the receiver plates does not perceptibly weaken the working of relay.

Now, we will use an uninsulated conductor, the same as a bare copper wire, for half the circuit; or, more properly, as shown, "ground " one-half the circuit, that is usually insulated, by making metallic contact between the inactive coppers, and add any num- 
ber of such plates, giving all the surface connection possible with the water for establishing a "ground," and yet in this case nearly all the current generated in battery goes the apparently longer route, by the resistance of relay, and having the smaller surface connections.

Neither is the relay operated by the divided single cell in the tub-the active zinc at battery and the active copper at relay, completing its circuit through relay, conductors, battery, key, active zinc, water, and active copper, back to relay-for, by cutting off all the main battery, we find this divided, or tub-cell, fails to operate the relay, even on the same adjustment as the "without wire" plan. I believe this theory is correct, that it is the repulsion of the polarized active ground plates of same name that resists the short-circuiting, as connecting the zincs of two cells together, and the coppers of same cells together by wire, will not produce good voltaic action. Then we may assume that the outgoing and incoming currents in the tub repel or bend each other apart, like the lines of force in a magnetic field; and, continuing the magnetic analogy, we have for the sending earth-plates north pole repelling north pole for the short circuit, while throngh the relay circuit we have, like the attraction between a north and south pole, the inviting route.

I believe that a certain fraction of current flows to relay, represented by one as a numerator, and the number of cells as a denominator; that is, a fixed part of current cannot overcome the resistance of same polarity, viz.: if a main battery of ten cells is used, one-tenth of its current cannot short-circuit in above arrangement, and if twenty cells, then one-twentieth flows out to receiver; the smaller portion of current being weakened by the resistance through which it flows, the same as if it had an insulated circuit.

\section{DIsCUSSION.}

Mr. Bear:-Now, I will add that with the wire plan, or "ground" plan; I have frequently connected all the coppers for which I had room in the tub. With these (indicating) several coppers, half a dozen or a dozen, we get surface, taking up all the room there (indicating). I have put plenty of common salt in the water, as it is well known to reduce the resistance, that, if possible, I might allow but little of the current to flow across the longer circuit, and, therefore, not leave anything to operate the relay; 
but the relay would operate much stronger that way than by the "without wire" plan. What I mean is, that to make the ground connection here as good as possible by saturating the water with salt, so that no more salt would be absorbed in the water, the relay would operate very strongly; I should judge at least half the battery current flowing to the relay. I would further add, that I have never had the opportunity of testing these two different plans, based upon, as I consider, the same principle. I have never had an opportunity to test it with instruments of precision; I have only used common telegraphic instruments, a relay and a sounder; but I tested it through salt water, water of the Atlantic Ocean, in a little bay, with about a half a mile of uninsulated wire, but not having a strong battery force-three or four cells only-I got all the results from it I expected to with such a small battery, but they were very weak. I used a sounder, and with three or four cells to the battery and half a mile of uninsulated wire, I was only able to affect the sounder with the very weakest adjustment; it would not affect the relay at all, I presume, by my not having battery enough, but the sounder certainly was affected at the distant end through the uninsulated wire immersed in the ocean water. I had a common laborer hear the sounder operate, so that it was not my prejudice that supposed that it operated. Those are the severest tests I have put the apparatus to. [Applause.]

The Chatrman :-Gentlemen, you have just heard Mr. Bear's very interesting remarks. A discussion is now in order on the subject.

Mr. James Kelly :-I wish to ask a question. The sounder was certainly affected, you say, and the relay not at all. I would like to ask how the sounder was affected without affecting the relay?

Mr. KeITH :-He had no relay.

Mr. BeAR:-That is a very pertinent question, because telegraph operators, these gentlemen know, generally use a sounder and relay together, but in this case I only used a sounder in a circuit by itself. The sounder was in the main circuit; I did not use the relay at all at the time; I used the sounder.

Mr. PARTz :-I don't think the explanation is quite satisfactory. The gentleman assumes that the current passes through water, that it takes the trouble of passing through the relay in order to return, while it might have a much easier route and go through the water; I don't think the current will take that trouble: I 
believe the current goes from one electrode to the other. The current that you get through the relay is simply an induction current. You want a much stronger battery in order to work this than you would by simply pushing the current through the water. That could be done with a very few elements. You have got this section of water into these lines of force, therefore, you have got to push your current with such force that it extends considerably into the water in order to produce an induced current; and that is what you get through your relay; that is my opinion.

Mr. BEar :-In reply, I would acknowledge my ignorance, if that current in the relay is produced by induction. The current in the relay is continuous. As I understand induction, when I would close the key of the battery there might be a temporary impulse, an instantaneous impulse of induction through the relay; but in this case the relay remains, as the operators call it, "closed." Therefore I take it it is not an induced current.

Mr. PARTz:-Yes; but you don't get any manifestations until you work your key.

Mr. Bear:-I just stated, and I intended to make it plain, that I did get a manifestation of the current by having, as every telegraph operator understands, the sounder or relay closed, and being properly adjusted. That is evidence that there is a continuous current flowing through the relay.

Mr. BAILEY :-I would like to ask the gentleman who has given this exhibition how closely those electrodes leading from the battery to the key have been placed together.

Mr. Bear :-Yes, sir ; I will state, one of our most prominent electricians made this experimentum crucis himself. I had not made it before, I believe; he took the copper and the zinc and interlocked them like my fingers (indicating) as closely as possible without touching, then separated them as far as possible. But apparently it made no difference in the operation of the relay when that test was made.

Mr. Barlex :-Was that test made while it was in the tub?

Mr. Bear :-Yes, sir.

Mr. Barley:-Do you know the distance? Was it the same as it is in this tub?

Mr. Bear:-Yes, sir; but I took a different battery. I had ten cells of the common large size-main battery cells, the common blue vitriol gravity battery.

Mr. BaILeY :-Then, I understand you it was many times the 
distance between the electrodes leading from the key and the battery; many times that distance, from them to and through the relay and return?

Mr. Bear :-The relay circuit was many times greater resistance than the short-circuit of the battery, between the transmitting earth-plates.

Mr. BAILEY :-That is exactly what I am arriving at. As I understand you, there was no perceptible difference in the action of the relay.

Mr. BEAR:-There might have been a difference, which would have been shown by a galvanometer.

Mr. BAILEY :-The relay was working with equal promptness in either case?

Mr. Bear :-Yes, sir.

The Chalrman :-It seems to me that this whole question is one of relative resistance, and had Mr. Bear had the benefit of a galvanometer to increase the amount of his knowledge upon the subject, he perhaps would have arrived at a different conclusion.

Mr. MaynaRD :-I would like to inquire of Mr. Bear whether he has used this system for actual communication by the Morse system over some considerable distance; whether he has not actually telegraphed with the Morse instruments and without insulation for a long distance?

Mr. Bear:-No, sir; I have not.

Mr. Maynard:-Another question. What do you consider is the practical application of this system?

Mr. Bear :-I consider its practical application to be in assisting in the insulation of telegraphic circuits.

Mr. MaYNARD :-Is there any reason why you cannot telegraph across the ocean as well as across the tub?

Mr. Bear:-From my theories, and I have studied the subject for several years, I do not know of any reason why not; and I find that the best authorities upon the subject, those that we find published even lately (I believe since the opening of this exhibition), have suggested the placing of one earth-plate in the northern region and the other away south. But that is on the old, or Morse, plan of telegraphing by relative resistances, as I understand it. This, my method, does not depend on the relative resistances, as we understand the term resistance or conductivity.

Mr. PReeCe:-What does it depend upon?

Mr. Bear:-I believe it depends upon the counter electro- 
motive force, or polarity; the meaning is the same. As the north pole of the magnet will repel a north pole, although if one north pole is strong enough, it will overcome the weaker north pole; so that if this electromotive force of the main battery is high enough, a great portion of it will overcome the opposing electromotive force of the plate of the same name.

Mr. KEITH :-I had understood from Mr. Bear, previous to reading his paper, that he had experimented with this in ponds of considerable size, so that his experiment has been in the water, and on a larger scale than here shown. I think that is what Mr. Maynard wished to get at-whether you had actually carried on an experiment of any considerable size ; that is, larger than the tub?

Mr. Bear :--Oh, yes. By the wire plan, but not without wire. I got so much better results with uninsulated wire, and you may readily imagine, by my explanation of this point, that I wanted commercial success. But my idea was that if I used this " withoutwire" plan it would only give me one circuit; whereas, we want many circuits. And if I succeeded in operating successfully the uninsulated plan, then I could use any number of circuits close together, so long as they were not in metallic contact.

The Chairman (Mr. W. D. Sargent):--I would ask if Mr. Preece desires to make any remarks upon the subject?

Mr. Preece :-I think the society would, perhaps, like to have the details of a practical experiment bearing on this subject; and I am sorry I was not present during the time the paper was read, for up to the present moment I quite fail to perceive in what this differs from our oldest notions of the mode of communication across water without wires.

It is now, I am almost ashamed to say how many years, but it was in the year 1853 (and 53 from 84 leaves 31 ), 31 years ago, there was a Mr. Lindsey, a Scotchman, who came to London with the notion, shared in by a great many people since, that he was going to make an enormous fortune, because he had discovered a mode of transmission across water without the aid of wires. He came to the electrical company, to which I was then attached, and made an experiment exactly similar, so far as I see, to that which has been made here. We gave him a tank about the size of this table, about 8 or 10 feet long, and about four feet wide, and in that tank he placed four copper plates, arranged exactly as shown here, but the instrument used was not a relay; it was an ordinary Wheatstone signal needle; and we certainly got effects through it, 
which showed distinctly that it was possible by such an arrangement as that to transmit electrical signals across water without the aid of wires at all; and the experiment was sufficient to justify its being tried on a larger scale. So he was allowed to experiment, I think, upon the river Tay, I can't quite recollect what river it was, but it was, at any rate, some river in Scotland. Two wires were located some few miles along the banks on either side, and the experiment was repeated, and was again successful. The only effects on the galvanometer were evidently less in actual practice than they were when the experiment was in the insulated tub or tank, such as we gave him. The result of that experiment was sufficient to prove the whole theory of the thing, but it was seen that it was not practical with the then instruments. I took a little interest in the matter at the time, but I had the impression that such an experiment was described, I think, in a very old and valuable book published in this country by Mr. Albert Vail; I think Mr. Morse, or somebody, if not Mr. Morse himself, made a very similar experiment herein. Anyhow that experiment remained in abeyance for a great many years, and it was only when the telephone was brought into existence, with its excessive sensitiveness, that we were induced to repeat the experiment.

It happened that a cable connecting the Isle of Wight, in the South of England, to the mainland broke. The Isle of Wight is a place where the Queen has one of her residences, and we are very oareful in maintaining telegraphic communication complete there. The Isle of Wight is shaped something like that. [Illustrating on blackboard.] Here is Southampton, there is a spot of land going out there called Hurst Castle, Southampton Castle coming up there, and there is the town of Portsmouth. [Indicating.] There is the town of Southampton, and there is Hurst Castle. This is the Isle of Wight, and this is Newport, the Queen's residence, and that place is Ryde. [Indicating.] Now wires come from Southampton to that place, and the cable crosses there; they go from Newport into Osborn and Ryde. A few go to Southampton and Portsmouth. Now, here was a very good opportunity to test this very fact; and I had the cable earth-plates placed in the sea, and the wire was carried to the end of the pier, with the cable plates there and there. [Indicating.] So the circuit was completed, with about a mile of sea there, and six miles of sea over there. [Indicating.] The operators were here. They had a telephone here, and a telephone there [indicating], 
and no sound could be obtained from the voice. With a bugle a faint sound was heard; but when we inserted a buzzer, something like one of the tuning-forks used by Mr. Delany to maintain his vibration, we obtained a buzzing sound, and by the use of the tuning-forks we succeeded in sending currents so rapid as to make sonorous vibrations, and then sounds were distinctly heard there. But when the key was manipulated by the operator at either station, then it was quite possible to transmit signals by making and breaking these buzzing sounds, and thereby to continue the correspondence and to continue the telegraphic communication. Unfortunately for the experiment, this cable that was broken was renewed and repaired that very day the experiment was made, so that we really never carried out this practically. We simply made an experiment as an experiment; but the experiment was so satisfactory that if this cable breaks again, then we shall certainly during the time that it is broken maintain telegraphic communication with the Isle of $\mathrm{W}$ ight through the sea circuit arrangement until the cable is repaired.

Now, there is just one little point in this that rather removes it from the category of Mr. Bear's experiment, or Mr. Lindsey's, and that is, that across here you have not absolutely an unbroken piece of water, but you have a cable. The cable was broken probably for the distance of a few fathoms, but at any rate there was a conductor separated by a few inches or a few feet, and it maintained communication across there. On the other hand, here you had an undoubted length of six miles.

Now, I do not see, at present, I may be wrong, in what respect this experiment differs from the one that has been described to you. If we have a river with banks running parallel, and we have an earth-plate there, and a conductor there in each bank, it is quite possible to transmit a current through, when the resistance of that length compares to the ratio of that length, and from all theoretical reasons, it is very easy to give the relation determining that and to show the condition of the strength of current; but I gather from Mr. Bear that he thinks the counter electromotive force is the cause of the matter. I have not the least doubt that it is. But it simply does so because the electromotive force, the reverse electromotive force, becomes exactly the same as his resistance. If you are using a bridge, and you are testing a current, that circuit may have an earth current in it, and if the earth current Hows in the same 
direction as the current you are testing, then your resistance is less than it ought to be; but if that earth current flows in the contrary direction, then your resistance is increased and is greater than it ought to be; so that the influence of counter electromotive force in a current is exactly the same as answers to the true resistance. This experiment has been described to you as in point of fact and theory exactly the same as that which governs the experiment I have given, and is the same as that which is supposed to be within the knowledge of those who read works on electricity, or even in the knowledge of those who make a practical application of the telegraph instruments. That experiment is simply an experiment for illustration of the practical demonstration of the truth of the theory by which we are able to communicate across water without the aid of conducting wires.

Mr. KeLLY :-If he has drawn this diagram correctly I don't see how he obtains the electromotive force.

\section{SECOND DISCUSBION.}

The Chairman (Mr. George C. Maynard):-Mr. Partz desires to make some remarks on the subject of telegraphing without wires, a subject that was introduced by $\mathrm{Mr}$. Bear yesterday.

Mr. PARTz:--As the subject was brought up before you, I thought it might not be out of place to set forth a little scheme of mine of telegraphing without cables through the water. I mentioned the matter yesterday as a sort of curiosity for the time being to Mr. Preece. I will make it as short as possible.

Suppose that this is an irregular section of the globe through its Northern Hemisphere; supposing that here you have Halifax, there Vancouver's Island, or any other point on the Northern Pacific coast, there the mouth of the Amor River in Siberia, and that a point on the west coast of Ireland. Now we have a continuous insulated conductor from Nova Scotia to Vancouver's 1sland. We have another insulated conductor from the Amor River to Ireland. Now, supposing the current passing through that conductor in that direction, that current must necessarily go through that conductor in that direction, that current must necessarily go around the globe, and consequently you can telegraph without a cable. The current would certainly not go back to Vancouver's Island or to Nova Scotia, that is, take land conductor, as it has a much easier way the other way. 
As I said before, it may be a mere curiosity for the present, but we do not know always what these will finally result in. $\mathrm{Mr}$. Delany, with his system, has certainly shown us that more can be done with one wire than was thought possible, and that any number of messages can be sent at the same time. The thing will look different when it is accomplished. Such a line might extend around the globe. You might work, say from the Congo River to Central America, by having a relay station at St. Helena. From Central America through the Pacific Ocean, having relay stations at the Islands and over to China, and from China then by land, and by short cables to the Congo River. For that continent I do not think will remain very long dark, and there will certainly be a telegraph somehow put through. A line might be established from the Cape of Good Hope to Buenos Ayres, and from Buenos Ayres to Valparaiso, and from Valparaiso to the South Sea Islands and Australia. I would like to hear any objections to that, if there are any. I have no doubt but that it will be put into practice, perhaps, before we arrive at 1900 . Perhaps in twenty or twenty-five years, something of that kind will be arrived at, because it is rational.

Mr. KeIrH :-There is one very pertinent objection to it, and that is that it has not been tried.

Mr. Partz:- It may be tried at any time now. There is nothing to interfere with it being tried.

The Chatrman :-I would like to ask one question. If this theory is true, will it not be quite practical to try it on some small dake and settle the question before you attempt to cross the ocean; will not that settle the theory just as well?

Mr. PARTZ:-I don't know whether that could so easily be tried on a small scale. It would be rather difficult to try it on a small scale. You could not get a circuit of that kind, it would be necessary to take in the globe.

Mr. Bear :-Mr. President, I believe the conditions are similar in a small body of water or earth as in a large-the largest, as the ocean, as suggested by Mr. Partz; or in a lake, or in a tub of water, the same conditions will obtain, I believe. This is simply the old method, which I quoted yesterday, of Professor Morse. Whether others were before him or not, I do not know. This is a matter of relative resistances, familiar to us all. That if two routes are offered for the electric impulse or current it will divide, according to Ohm's law, as Mr. Partz truly says, instead of run- 
ning the greater distances between these earth connections, it will take a shorter distance, and it is perfectly rational and ought to be tried.

The Chatrman :-Gentlemen, as we seem to have gone back to yesterday's business for a moment, I thought it might not be out of place to correct one misapprehension, which was brought up yesterday by the paper on underground wires read by $\mathrm{Mr}$. Callender, and which I have heard expressed about twice a day for three or four weeks, and that is that the underground wire question has been settled once for all in Washington. The electrical people seem to have gotten the idea that somebody there has settled the question, and they are very fond of referring to that.

The facts are as follows: That the underground question in Washington has been thoroughly unsettled. I think some six or eight years ago Captain Green, who is quoted as the man who settled the question there, came to me to see what books I had on the subject. In looking over what I had, he picked out several volumes of the Journal of the London Electrical Engineers' Society. In that journal he found some report made by Mr. Preece on laying underground some telegraph wires between London and Manchester. He said at once that that settled the question, and that there was nothing more to be said, and he wrote a report to that effect. I think that he has never changed his opinion since then. Whether he has obtained any additional light on the subject, I would not undertake to say. At all events, the District Commissioners, who are the controlling military power of the District, have been issuing orders about semi-annually ever since, that no more wires should be strung overhead. Since they gave such an order the number of poles in the District, I suppose, have been doubled and quadrupled a good many times over, and what is of a good deal of importance, the poles have been erected by the National Government. The District government has always been erecting poles, and the number erected by the government has been very much larger than all the other poles in the city together, and the government has been setting up poles almost up to this day, and I think that they contemplate setting up more poles. During all this time the Commissioners have never, to my knowledge, asked Congress for a dollar of money, even to try any experiment with underground wires. But the great pressure that they have kept upon the private corporations has very much hindered the setting of poles, and has brought about quite a number of experiments 
with underground work. Two or three of the telegraph companies have laid some small number of wires in various ways underground. Some of them have worked, and some of them have not worked. The Waring Cable Company have, within the last year, been laying some few wires-three, four, or five wires, to connect some of the departments, at their own expense. The Telephone Company, under the pressure of the authorities, and under the general pressure of the demands for a greater number of wires, has made an experimental line of several hundred wires for about a mile with moderate success. They are preparing to lay some more wires, but the fact remains that the wires in Washington are not all underground. There does not seem to be any immediate prospect that they will go there. So that the gentlemen who are anxious for this, that the wires can and will work underground, will do well to look to some other city than Washington. 